\title{
THE HIGH CURRENT CYCLOTRON COMPLEX FOR AN ELECTRONUCLEAR WAY OF PRODUCTION OF ENERGY
}

\author{
Y.G.Alenitsky, A.A.Glazov, V.P.Dmitrievsky, N.L.Zaplatin, V.V.Kalinichenko, L.M.Onischenko, \\ N.A.Rusakovich, DLNP, JINR, Dubna, Russia
}

\begin{abstract}
The prospects of development of an electronuclear method of energy production are considered. The tentative estimation show, that use of accelerators with energy of the protons beam (1-10) MW enables to gain a thermal power of subcritical assembly up to $1 \mathrm{GW}$. In this case as divided materials are used $\mathrm{Th}^{232}[1]$ or $\mathrm{U}^{238}[2,6]$, which stores essentially exceed stores of isotopes used in a nuclear power engineering now $\left(\mathrm{U}^{235}, \mathrm{U}^{233}\right)$.

The offered accelerator - cyclotron complex - now is the cheapest and reliable installation for producing of proton beams with power of some MW. A peak current $1.8 \mathrm{~mA}(\mathrm{~W}=590 \mathrm{MeV})$ of the accelerated protons on a cyclotron PSI (Switzerland) shows that the key physical problems for producing such a beam on a cyclotron are solved.

The basic parameters of the complex are based on the results of development of the project "Supercyclotron" which was made in $80-90$ years. The offered complex consists of three isochronous cyclotrons with final energies of protons 15, 60 and $800 \mathrm{MeV}$.
\end{abstract}

\section{ELECTRONUCLEAR WAY OF ENERGY PRODUCTION}

\subsection{Introduction}

In spite of the fact that use of an atomic energy production inevitably reduces in occurrence of radioactive contamination of a medium, already now nuclear power resources of the developed countries make in France - 75 $\%$, in Belgium $-60 \%$, in Sweden - $46 \%$, in German - 33 $\%$, in Japan $-26 \%$, in USA - $21 \%$, in Russia $14 \%$ [3] from common energy consumption.

The basis of an atomic energy production is the process of fission of transuranium elements, at which the thermal energy makes $0.8 \mathrm{MeV} / \mathrm{nucl}$, that corresponds to a modification of a binding energy of nucleons in the kernel at fission. Taking into account that the mass of a nucleon is equal $1,67 * 10^{-24} \mathrm{~g}$, and $1 \mathrm{MeV}=1,6 * 10^{-13} \mathrm{~J}$, indicated there thermal energy corresponds $7,66^{*} 10^{10} \mathrm{~kJ} / \mathrm{kg}$, or $1,83 * 10^{7} \mathrm{kcal} / \mathrm{kg}$ (thermal energy at burning $1 \mathrm{Kg}$ of coal are equal $\left.8 * 10^{3} \mathrm{kcal}\right)$.

The effectiveness of nuclear fuel is determined by a type of a nuclear reaction. So, for example, for a thermonuclear fusion reaction $(\mathrm{d}, \mathrm{T})$ the complete energy release makes $17,6 \mathrm{MeV}$ on five nucleons [4], participating in process, that is $3,52 \mathrm{MeV} / \mathrm{nucl}$, that fore times more than an energy release of process of fission. However, as in a fusion reaction the neutron carries away $14,1 \mathrm{MeV}$, this energy advantage, in comparison with a response of fission, can be implemented, only at use of these neutrons in a reaction of fission. The technological difficulties at making long-lived, dense and hightemperature plasma are not overcome completely, despite of numerous investigations in many physical laboratories.

Investigations of a possibility of use obtained on accelerators $\mu$ - mesons for a fusion reaction $(\mu-d, T)$ have shown, that the sum of input and output energy at the present stage of this investigations not effective, as the expenditures of an energy on production one $\mu$ - meson $(5 \pm 1) \mathrm{GeV}$ [5], and the amount of fusion reactions during life - meson does not exceed 160.

Thus, the nuclear power engineering will be based in the foreseeable future on processes of fission of transuranium elements. Central scientific problems, which should be solved in a nuclear power engineering, will be:

1. Safety of nuclear reactors at use of a chain reaction;

2. Transmutation or underground storage of radioactive waste (ecological safety).

The first problem is bound to development of new types of reactors with a boosted degree of safety or complete refusal from a self - sustaining chain reaction (subcritical assembly, electronuclear method).

Second - is solved by means of nuclear transmutation of long -life radioactive isotopes in neutron generators, which are based on charge particles accelerators or on nuclear reactors.

\subsection{Electronuclear method}

The electronuclear method of production of an energy is founded on process of fission of the kernels in subcritical assembly $(\mathrm{k}<1$, where $\mathrm{k}$ - a multiplication factor of neutrons) at presence of an exterior source of neutrons. At fission of one kernel is produced $190 \mathrm{MeV}$ $\left(3,04 * 10^{-11} \mathrm{~J}\right)$ energy as a kinetic energy of fragments of fission, which turns in thermal on length of their run $(\sim 100 \mu)$.

For a thermal energy $1 \mathrm{GW}\left(10^{9} \mathrm{~J} / \mathrm{sec}\right)$ production it is necessary to produce $10^{9} / 3,04 * 10^{-11}=3,29 * 10^{19}$ acts of 
fission, that corresponds to include in process of fission $3,29 * 10^{19}$ neutr./s. The operating proton accelerators on an energy of beam up to $1 \mathrm{GeV}$ (see tab. 1) have now maximum intensities of protons (1-2) $\mathrm{mA}\left(6 \cdot 10^{15} \div\right.$ $\left.1,2 \cdot 10^{16} \mathrm{p} / \mathrm{sec}\right)$. An amount of evaporation neutrons, which can be received at such intensities does not exceed $10^{18}$ neutr./s. It is visible, that even without the account of an absorption of neutrons by nuclear processes attendant fission, for making an engine installation of the indicated power $(1 \mathrm{GW})$ the additional amplification of an exterior source of neutrons in tens time is necessary.

Such additional amplifier of an external neutron beam can be served by subcritical assembly, where the external neutron beam multiplied on coefficient $1 /(1-\mathrm{k})$ $(\mathrm{k}=0.9 \div 0.95)$. The effect of amplification of a neutron density allows to consider a possibility of development of electronuclear generator with a thermal rating $1 \mathrm{GW}$ at intensity of proton beams of the accelerator in an interval $1 \div 10 \mathrm{~mA}$ with an energy $(0,8 \div 1,0 \mathrm{GeV})$. The basic physical problem, which should be solved before definition of necessary intensity of beam of the accelerated particles, is the theoretical and experimental investigation of the subcritical assembly with the purpose of definition optimum the value of the subcritical and modification by this the subcritical in time by operation of installation. The investigation and sentences on construction of the subcritical assembly are available in many physical institutes [7-12].

\section{MODERN NEUTRON GENERATORS}

\subsection{Parameters of beams and accelerators used in neutron generators}

The main parameters of proton beams in existing neutron generators are shown in Table 1 [13]. Parameters of a beam of the phasotron JINR, which works now in a LNP JINR there are shown.

It is possible to see from Table 1 and publications regarding high-current accelerators that:

1. On JINR phasotron beam it is quite possible to make the generator of neutrons, for realization of experiments with assembly implementing an electronuclear method of energy production.

2. The proton beam of a maximum energy is obtained on a cyclotron PSI and, on last data, the

Table 1. magnification of a power of a beam is expected [14];

3. The proton beam on linac (Los Alamos USA) is obtained considerably of smaller power, and the magnitude of a beam current is restricted by losses at acceleration, there are sentences on a diminution of losses, but it requires study and realization of fundamental experiments.

Now, as it is scored in $[3,15]$ etc. it is necessary to initiate with development of an experimental complex the accelerator - subcritical assembly for model operation of the plant on small (50 - 500) MW level of an energy. The coming years as the accelerator for such experiment it is necessary to use a stage of cyclotrons, as only cyclotron has required parameters [16].

The modern understanding of influence of a space charge on dynamics of a beam in a cyclotron demonstrates an actual possibility of magnification of a current of an accelerated beam up to a level $10 \mathrm{~mA}$ and more [14]. Thus there is obvious an expediency of use of cyclotrons, as most economic, reliable, compact and, that is important, concerning cheap installations at all stages of acceleration.

\subsection{Scheme and basic parameters of the high- current cyclotron complex}

Now in laboratories of the world some plans of cyclotron complexes for subcritical assembly driving are studied [17]. All plans have three steps of acceleration, that is stipulated, in basic, possibility to optimize structures magnetic and accelerating of systems depending on an energy in view of influence of a space charge.

Basis for choice of parameters of the present design are the results of operations on projection of a supercyclotron in a LNP JINR, which were carried out in the beginning 80 years [18], where as an injector the linac with a energy of a beam $50 \mathrm{MeV}$ was chosen. Then the models of two sectors of a magnet of a cyclotron part of a complex and resonator in a scale 1:5 were made. The outcomes of model operation of a magnetic system of a supercyclotron have shown, that the generated magnetic field ensures frequency of axial oscillations Qz in limits 1.35- 1.45 on all radii. Offered now plan of 3 stage cyclotron complex driver on energy of protons $800 \mathrm{MeV}$ with beam current (10-30) mA consists of:

\begin{tabular}{|l|c|c|c|c|c|c|}
\hline & $\begin{array}{c}\text { IPNS } \\
\text { Argon } \\
\text { USA }\end{array}$ & $\begin{array}{c}\text { KENS } \\
\text { KEK } \\
\text { Japan }\end{array}$ & $\begin{array}{c}\text { MLNSCE } \\
\text { Los Alamos } \\
\text { USA }\end{array}$ & $\begin{array}{c}\text { ISIS } \\
\text { England }\end{array}$ & $\begin{array}{c}\text { SINQ } \\
\text { PSI } \\
\text { Switzerland }\end{array}$ & $\begin{array}{c}\text { JINR } \\
\text { Russian } \\
\text { Federation }\end{array}$ \\
\hline The accelerator & $\begin{array}{c}50 \mathrm{MeVlinac}+ \\
\text { synchrotron }\end{array}$ & $\begin{array}{c}40 \mathrm{MeVlinac}+ \\
\text { synchrotron }\end{array}$ & $\begin{array}{c}800 \mathrm{MeV} \\
\text { linac+storage ring }\end{array}$ & $\begin{array}{c}70 \mathrm{MeVlinac}+ \\
\text { synchrotron }\end{array}$ & $\begin{array}{c}72+590 \mathrm{MeV} \\
\text { cyclotrons }\end{array}$ & $\begin{array}{c}680 \mathrm{MeV} \\
\text { phasotron }\end{array}$ \\
\hline Energy $\mathrm{p}(\mathrm{MeV})$ & 450 & 500 & 800 & 800 & 590 & 680 \\
\hline Beam current $(\mu \mathrm{A})$ & 15 & 4.6 & 70 & 200 & 1500 & 3.2 \\
\hline Beam power $(\mathrm{kW})$ & 6.8 & 2.3 & 56 & 160 & 885 & 2.2 \\
\hline
\end{tabular}


1. 4 sectors cyclotron - injector on an energy of protons $15 \mathrm{MeV}$;

2. 4 sectors isochronous cyclotron accelerating a proton beam up to an energy $60 \mathrm{MeV}$;

3. 10 sectors isochronous cyclotron with a maximum energy of protons $800 \mathrm{MeV}$.

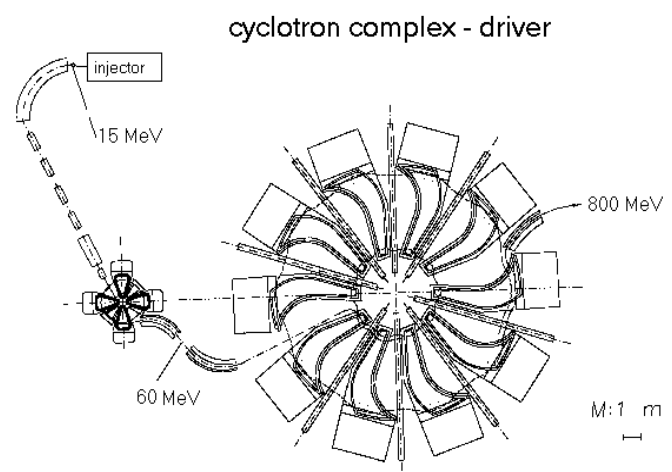

Figure 1: Scheme of 3 stages cyclotron complex.

The scheme of 3 stages cyclotron complex is shown on Fig. 1 and the basic parameters of cyclotrons submitted in Table 2. The parameters of the complex can be changed during optimization.

\section{REFERENCES}

[1] C.Rubbia, Contribution to the Las-Vegas Conf. 1994. [2] V.P.Dmitrievsky, N.V.Sergeeva " Uranium - 238 as a radiant of deriving of an energy by an electronuclear method ", JINR Rapid communication , V.5,6 [97] - 99, p. $85-91$.

[3] V.I.Subbotin" The accelerators can make a nuclear power engineering by more safe ", JINR, P199-97.
[4] L.A.Arcimovich, "Controllable thermo- nuclear reactions ", Moscow, 1961, p.6.

[5] Y.V.Petrov, Materials XIV of winter school, Leningrad, 1979, p. 139.

[6] A.M.Baldin, private communication.

[7] F.Carminati, C.Geles, R.Klapish at al, CERN/AT/9347 (ET), 1993.

[8] S.Àndriamonje at al, CERN/AT/94-45 (ET), 1994.

[9] P.N.Alekseev, A.G.Aseev, at al, ÈÀÝ - 6110/3, 1998.

[10] V.S.Barashenkov, A.Polanski, I.V.Puzynin,

A.N.Sisakian, JINR, E-2-99-206, 1999.

[11] Yu. G.Alenitsky et al, "High current deuteron cyclotron complex... ", JINR, E9-96-370, Dubna, 1996.

[12] K.D.Tolstov, JINR Rapid communication, 5 [62] 93, Dubna, 1993.

[13] I.S.K. Gardner, " A review of spallation neutron source accelerators ", Proc. of the EPAC 98, p 98-102.

[14] Th.Stammbach, " High intensity problems..", Proc.of the 15th Conf. Of Cycl. and their Applic, p369-376, Caen 1998.

[15] V.N.Mihailov, " Powerful bundles of neutrons with use of accelerators ", JINR Rapid communication, V.6 (80) - 96, p.17-22.

[16] Y.G.Alenitsky, " Isohronous cyclotrons for electronuclear installation ", Transactions II of a scientific seminar of V.P.Sarancev memory, Dubna, Ä9-98-153, p. 89-96.

[17] M.K.Graddock, " Critical Beam Intensity...", Proc.of the 15th Conf. Of Cycl. and their Applic, p 377-380, Caen, 1998.

[18] A.A.Glazov et al., Proc. of the V Conf. on the Accelerators, Dubna, 1976, vol.1, p.123, Sciense, 1977.

Table 2. The basic parameters of a high-current cyclotron complex.

\begin{tabular}{|c|c|c|c|c|}
\hline № & & $\mathrm{Ci}-15$ & $\mathrm{C}-60$ & $\mathrm{C}-800$ \\
\hline 1 & Energy of injection - extraction $(\mathrm{MeV})$ & $0.5-15$ & $15-60$ & $60-800$ \\
\hline 2 & Radius of injection - extraction (m) & $0.2-1.36$ & $1.36-2.62$ & $2.62-6.5$ \\
\hline 3 & Gap of a magnet $(\mathrm{m})$ & 0.03 & 0.05 & 0.09 \\
\hline 4 & Number of sectors & 4 & 4 & 10 \\
\hline 5 & Angle of sector inj./extr. $\left(^{\circ}\right)$ & 30 & $32 / 36$ & $11 / 14$ \\
\hline 6 & Angle of a spiral inj/extr $\left(^{\circ}\right)$ & 0 & 0 & $-20 /+50$ \\
\hline 7 & Frequency of a HF-system (MHz) & 49.5 & 49.5 & 49.5 \\
\hline 8 & Harmonic of acceleration & 6 & 6 & 6 \\
\hline 9 & Number of the basic resonators & 4 & 2 & 6 \\
\hline 10 & Voltage on the resonator (inj/extrac) (kV) & $100-150$ & $125-250$ & 750 \\
\hline 11 & Power of HF-losses in the resonator (MW) & 0.04 & 0.03 & 1.0 \\
\hline 12 & Number of flat-top resonators & - & 2 & 2 \\
\hline 13 & Harmonic of flat-top resonator & - & 18 & 18 \\
\hline 14 & An energy gain per turn $(\mathrm{MeV})$ & $0.8-1.4$ & $0.5-1.0$ & 4.5 \\
\hline 15 & Beam power (MW) & 0.15 & 0.6 & 8 \\
\hline 16 & Power consumption of magnet (MW) & 0.08 & 0.45 & 2.0 \\
\hline
\end{tabular}

